\title{
Dynamic characterization of aortic annulus geometry and morphology with multimodality imaging: Predictive value for aortic regurgitation after transcatheter aortic valve replacement
}

\author{
Ahmad Masri, MD, ${ }^{a}$ Paul Schoenhagen, MD, ${ }^{\text {a,b }}$ Lars Svensson, MD, PhD, ${ }^{\text {a }}$ Samir R. Kapadia, MD, ${ }^{a}$ \\ Brian P. Griffin, MD, ${ }^{\mathrm{a}}$ E. Murat Tuzcu, MD, ${ }^{\mathrm{a}}$ and Milind Y. Desai, MD ${ }^{\mathrm{a}, \mathrm{b}}$
}

\begin{abstract}
Background: Patients undergoing transcatheter aortic valve replacement (TAVR), as compared with those undergoing surgical aortic valve replacement (AVR), have higher postprocedural aortic regurgitation (AR), associated with higher mortality. We hypothesized that reduced annular deformation is associated with higher postprocedural AR and sought to assess incremental value of assessment of aortic annular deformation in prediction of post-TAVR AR.
\end{abstract}

\begin{abstract}
Methods: We included 87 patients with high-risk severe aortic stenosis (AS) ( $81 \pm 10$ years, $54 \%$ men) who underwent preprocedural echocardiography and contrast-enhanced (4-dimensional) multidetector computed tomography (MDCT) of the aortic root, followed by TAVR $(n=55)$ or surgical AVR $(n=32)$. On MDCT, min$\mathrm{imal} /$ maximal annular circumference, circumferential deformation (maximum-minimum over cardiac cycle), and eccentricity (largest/smallest diameter during systole) were calculated. Degree of commissural/annular calcification was graded semiquantitatively (scale 1-3). Oversizing/undersizing of the prosthesis during TAVR was assessed.
\end{abstract}

Results: Pre-AVR aortic valve area $\left(0.6 \pm 0.1\right.$ vs $\left.0.6 \pm 0.1 \mathrm{~cm}^{2}\right)$, mean aortic valve gradient ( $46 \pm 14 \mathrm{vs} 45 \pm 11$ $\mathrm{mm} \mathrm{Hg})$, AR ( $1 \pm 0.8$ vs $0.9 \pm 0.7)$, maximal annular circumference ( $8 \pm 1$ vs $7.9 \pm 0.8 \mathrm{~cm})$, annular deformation $(0.3 \pm 0.1$ vs $0.3 \pm 0.1 \mathrm{~cm})$, eccentricity $(1.2 \pm 0.1$ vs $1.2 \pm 0.1)$, commissural $(2.1 \pm 0.6$ vs $2 \pm$ $0.7)$, and annular calcification scores $(1.7 \pm 0.8$ vs $1.7 \pm 0.8)$ were similar in TAVR and surgical AVR groups ( $P=$ not significant). A higher proportion of patients had $\geq$ mild AR in the TAVR than in the surgical AVR group $(58 \%$ vs $34 \% ; P<.03)$. In TAVR patients, reduced annular deformation $(P=.01)$ predicted postprocedural AR, in addition to prosthesis undersizing $(P=.03)$ and higher annular calcification $(P=.03)$.

Conclusions: Residual post-TAVR AR is predicted by reduced aortic annular deformity, higher annular calcification, and prosthesis undersizing. Pre-TAVR 4-dimensional annular assessment aids in prediction of post-TAVR AR. (J Thorac Cardiovasc Surg 2014;147:1847-54)

Video clip is available online.

Recent trials have established transcatheter aortic valve replacement (TAVR) as a viable alternative for patients with severe, symptomatic aortic stenosis (AS) and high operative risk. ${ }^{1-4}$ In addition, it has been recently demonstrated that post-TAVR aortic regurgitation (AR) is associated with

\footnotetext{
$\overline{\text { From the Heart }}$ and Vascular Institute ${ }^{\mathrm{a}}$ and Imaging Institute, ${ }^{\mathrm{b}}$ Cleveland Clinic, Cleveland, Ohio.

Disclosures: Authors have nothing to disclose with regard to commercial support. Received for publication March 4, 2013; revisions received April 25, 2013; accepted for publication May 31, 2013; available ahead of print July 17, 2013.

Address for reprints: Milind Y. Desai, MD, Tomsich Department of Cardiovascular Medicine, Heart and Vascular Institute, Cleveland Clinic, 9500 Euclid Ave, Desk J1-5, Cleveland, OH 44195 (E-mail: desaim2@ccf.org). $0022-5223 / \$ 36.00$

Copyright (c) 2014 by The American Association for Thoracic Surgery http://dx.doi.org/10.1016/j.jtcvs.2013.05.047
}

worse outcomes. ${ }^{4}$ Because transcatheter implantation is performed without direct visualization of the device landing zone, preprocedural and intraprocedural imaging is critical, ${ }^{5}$ for which multimodality imaging (angiography, transthoracic/transesophageal echocardiography [TEE], and multidetector computed tomography [MDCT]) is routinely used. ${ }^{5}$ The procedural goal is secure, coaxial fit of the stent valve at the aortic annulus and root. Recent studies have examined imaging-derived predictors of procedural complications and specifically post-TAVR AR. ${ }^{6-8}$

We sought to assess whether patients undergoing TAVR had higher degree of postprocedural AR, compared to those undergoing surgical aortic valve replacement (AVR). Although it is known that aortic annulus geometry changes during the cardiac cycle, ${ }^{6,9,10}$ most of the data are derived from static images at a single cardiac phase. Recent advances in software technology allow advanced time-resolved 3-dimensional computed tomographic (CT) reconstructions (ie, 4-dimensional reconstructions), by integration and interpolation of multiple image sets along the cardiac cycle. We 


\section{Abbreviations and Acronyms \\ $\mathrm{AR}=$ aortic regurgitation \\ AS = aortic stenosis \\ AVR = aortic valve replacement \\ $\mathrm{CT}=$ computed tomography \\ LVOT $=$ left ventricular outflow tract \\ MDCT $=$ multidetector computed tomography \\ TAVR $=$ transcatheter aortic valve replacement \\ TEE = transesophageal echocardiography \\ VTI = velocity time interval}

hypothesized that a detailed geometric analysis of such data could provide insight into the impact of differences in aortic annular deformability in patients with AS. In turn, such an insight could improve our understanding of post-TAVR paravalvular AR.

\section{METHODS}

Eighty-seven consecutive patients with severe symptomatic AS, referred for evaluation for surgical versus percutaneous valve replacement, were included in this observational study. Severe AS was confirmed and severity was graded according to established echocardiographic guidelines. ${ }^{11}$ Patients deemed to be at high surgical risk were included if they had undergone clinically indicated comprehensive echocardiography and contrastenhanced MDCT of the aortic root at our institution within 1 week of each other. According to current protocols, we excluded patients with bicuspid aortic valve morphology. ${ }^{1-4}$ Patients with advanced renal insufficiency or other contraindications to intravenous contrast dye were also excluded. The final population consisted of high-risk patients with severe AS who underwent either TAVR $(n=55)$ or conventional surgery $(n=32)$. Clinical, demographic, and imaging data were collected. Surgical risk was assessed and an additive EuroSCORE was calculated. ${ }^{12}$ This observational study was approved by the institutional review board, with waiver of individual informed consent.

\section{Preprocedural Transthoracic Echocardiography}

Surface echocardiograms were obtained using commercially available systems (Siemens, Erlangen, Germany; General Electric, Milwaukee, Wis; and Philips, Best, The Netherlands). Left ventricular ejection fraction was calculated according to American Society of Echocardiography guidelines. ${ }^{13}$ Peak and mean transaortic valvular gradients were measured using continuous wave Doppler in standard views. Velocity time integrals (VTI) across the aortic valve (using continuous wave Doppler) and left ventricular outflow tract (LVOT; using pulsed wave Doppler) were recorded. LVOT diameter was measured from the parasternal long-axis during midsystole and LVOT area was derived. Aortic valve area was calculated using the continuity equation: $\left(\right.$ LVOT diameter ${ }^{2} \times 0.786 \times$ LVOT $_{\text {VTI }}$ /Aortic valve $\mathrm{VTI}$. Degree of AR was recorded on a scale of I to IV, using multiple Doppler and 2-dimensional criteria. All measurements were performed according to guidelines. ${ }^{11,14}$

\section{MDCT Acquisition and Analysis}

Image acquisition. All subjects were scanned on standard MDCT scanner (Definition Dual Source/Definition Flash, Siemens Medical Solutions, Erlangen, Germany; or Brilliance 256-slice, Philips Medical Systems, Best, The Netherlands) after administration of iodinated contrast (80-100 mL of Ultravist 370 ) at 4 to $5 \mathrm{~mL} / \mathrm{s}$ followed by 30 to $50 \mathrm{~mL}$ of normal saline. Bolus tracking technique using a region of interest in the ascending aorta was used, and scanning (from the carina to the mid left ventricle) was initiated in the craniocaudal direction during a single inspiratory breathhold. Spiral data were acquired with retrospective electrocardiogram gating using the following parameters: gantry rotation time $=270$ to 330 ms; beam collimation ranging from $128 \times 0.6 \mathrm{~mm}$ to $32 \times 0.6 \mathrm{~mm}$; tube voltage $=100$ to $120 \mathrm{kVp}$; tube current adjusted per patient weight; and beam pitch of 0.2 to 0.5 . Electrocardiogram-based tube current modulation was used for all patients, with maximum current turned on between $30 \%$ to $70 \%$ phases of the cardiac cycle (hence maintaining image quality during the systolic phases). For the remaining phases, the current was reduced. Images were reconstructed during 10 phases of the cardiac cycle with a section thickness of $0.75 \mathrm{~mm}$. Radiation in the study sample was $<12$ mSEV.

Image analysis. Advanced MDCT image processing was performed using Ziostation PhyZiodynamics software (Qi Imaging, Redwood City, Calif). Each volume of the 10-phase data set was deformably registered to both neighboring phases, using a cyclic method whereby the first and last series were considered neighbors. Subsequently, a noise reduction algorithm was applied followed by improvement in motion coherence using interpolation of 4 additional phases between the original phases based on the registered voxels. These first 2 steps resulted in a newly generated data set consisting of 50 phases. To generate the dynamic measurement data, the user activated a tool to define the aortic annulus to calculate the circumference and area, or the tool could be used to place 2 points to calculate a length. Aortic annular plane was defined on a double oblique reconstruction at the level of the virtual basal ring, as previously described. ${ }^{15,16}$ In cases of annular calcification, the annular tracing excluded areas of calcification from the measurements. All data was exported as .csv files and uploaded into Excel for statistical processing.

For the current study, the following parameters were measured (Figure 1 and Videos 1 and 2): maximal and minimal aortic annular circumference, delta annular circumference (maximum-minimum over the cardiac cycle, representing the deformation of the annulus through the cardiac cycle), maximal and minimal aortic annular area, delta annular area (maximumminimum over the cardiac cycle), largest and smallest diameters of the aortic annulus (maximum and minimum measurements for both), delta annular diameters (maximum-minimum diameter over the cardiac cycle), and eccentricity index (ratio of largest to smallest diameter at $40 \%$ systolic phase). Using established valve circumference ( $72 \mathrm{~mm}$ for $23-\mathrm{mm}$ and $82 \mathrm{~mm}$ for 26-mm prosthetic valve), percentage of prosthetic valve versus aortic annulus oversizing (positive percentage) and undersizing (negative percentage) was calculated using the following formula: (prosthetic valve circumference/annular circumference -1$) / 100 .{ }^{7}$ Additionally, degree of leaflet calcification was semiquantitatively assessed, using the following grades: 1: single lesion $<5 \mathrm{~mm}, 2$ : lesion $>5 \mathrm{~mm}$, or affecting 2 leaflets, 3 : severe calcification affecting 3 leaflets. Similarly, the degree of aortic annular calcification was assessed as follows: grade 1,1 or several lesions $<5$ $\mathrm{mm}$; grade 2, 2 to 3 lesions $>5 \mathrm{~mm}$; and grade $3,>3$ lesions $>5 \mathrm{~mm}$.

\section{Surgical AVR, TAVR, and Intraprocedural TEE}

For the purpose of this study, all echocardiographic measurements were remeasured by an experienced echocardiographer in a blinded manner. Surgical AVR was performed in a standard fashion under transesophageal guidance and general anesthesia. TAVR implantation (using the Edwards Sapien valve; Edwards Lifesciences, Irvine, Calif) was performed using general anesthesia and intraprocedural TEE as described. ${ }^{5}$ Annular size was reconfirmed using intraprocedural TEE on a zoomed long-axis midsystolic frame (hinge point to hinge point). Prosthetic valve size selection was performed as previously described $\mathrm{d}^{5}: 23-\mathrm{mm}$ prosthesis for annuli measuring 18 to $21 \mathrm{~mm}$ and 26-mm prosthesis for annuli measuring 22 to $25 \mathrm{~mm}$. By means of fluoroscopic and TEE guidance, the deployment of the prosthetic valve was ascertained, according to guidelines. ${ }^{17}$ Subsequently, positioning of the valve was retrospectively assessed on long-axis TEE 


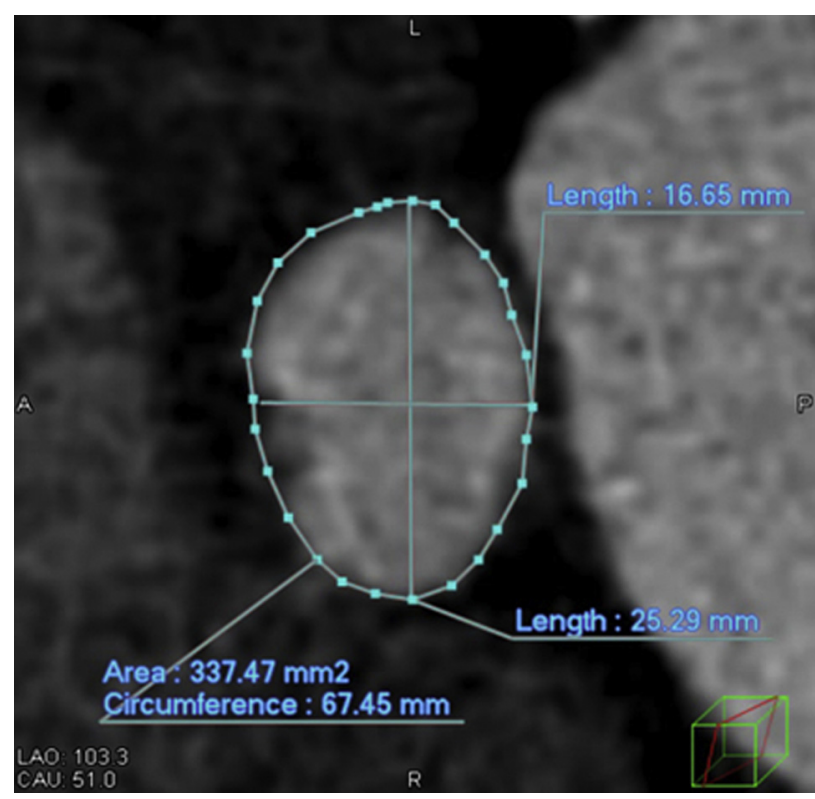

FIGURE 1. Four-dimensional multidetector computed tomographic image of the aortic annulus in a patient with severe aortic stenosis demonstrating various annular measurements including largest/smallest diameter, circumference, and area.

view and right anterior oblique projection of the intraprocedural cineangiogram. A ratio of valve depth below the annulus to total prosthetic valve length was measured in each patient. If the ratio was $\geq 60 \%$, the device was considered malpositioned, according to published data. ${ }^{6}$

In both groups, degree and location (paravalvular vs central) of postprocedural AR was again ascertained on a scale of I to IV using multiple Doppler and 2-dimensional criteria, as described above. In addition, offline measurement of vena contracta (for paravalvular AR) was made in all patients.

\section{Postprocedural Echocardiography}

A postprocedural, predischarge echocardiogram was also performed in all patients, (typically postprocedural day 2-3) in a manner similar to preprocedural echocardiography. Degree of AR (including paravalvular AR) was ascertained on a scale of I to IV, according to guidelines using multiple 2-dimensional, color and Doppler criteria. ${ }^{11,13,14}$ In addition, offline measurement of vena contracta (for paravalvular AR) was made in all patients.

\section{Statistical Analysis}

All values presented are the mean \pm standard deviation for continuous variables and percentage for categorical variables. Two independent samples test was used to compare continuous variables. The $\chi^{2}$ test was used for comparison of categoric variables. In addition, interobserver and intraobserver (A.M. and M.D.) reproducibility of various MDCT parameters (annular area and circumference) were measured using the BlandAltman method. Receiver operator characteristic curve analysis was performed to test the association between dependent variable (post-TAVR $\mathrm{AR}$ ) and continuous variable (potential predictors). Univariable logistic regression analysis was initially used to determine the association between dependent variable (residual post-TAVR AR) and potential predictors. Subsequently, predictors with a $P$ value $<.05$ on univariable analysis were entered into the multivariable model. All $P$ values were 2 sided. Data assembly statistical comparisons were performed with SPSS version 11.5 (SPSS Inc, Chicago, Ill).

\section{RESULTS}

\section{Baseline Characteristics}

The baseline clinical and echocardiographic characteristics of the total group, as well as the 2 subgroups, TAVR and high-risk surgical AVR, are shown in Tables 1 and 2. All patients were symptomatic on maximally tolerated medical therapy. No patient had post-CT scan nephrotoxicity requiring dialysis. In all patients, the aortic valve disease was predominantly AS. There were no patients with severe mitral regurgitation. The baseline MDCT characteristics are shown in Table 3. Intraobserver (A.M.) and interobserver (M.D.) reproducibility of minimal and maximal annular area was assessed using the Bland-Altman method (Figure 2, $A$ and $B$ ).

TABLE 1. Baseline clinical characteristics of the study population

\begin{tabular}{|c|c|c|c|c|}
\hline Variable & Total group $(\mathbf{n}=87)$ & Surgical AVR $(n=32)$ & TAVR $(\mathbf{n}=55)$ & $P$ value \\
\hline Age $(y)$ & $81 \pm 10$ & $84 \pm 6$ & $80 \pm 11$ & .06 \\
\hline Male gender & $47(54 \%)$ & $19(59 \%)$ & $28(51 \%)$ & .3 \\
\hline Hypertension & $70(80 \%)$ & $27(84 \%)$ & $43(78 \%)$ & .3 \\
\hline Diabetes mellitus & $29(33 \%)$ & $10(31 \%)$ & $19(35 \%)$ & .5 \\
\hline Myocardial infarction & $18(21 \%)$ & $7(22 \%)$ & $11(20 \%)$ & .5 \\
\hline Stroke & $22(25 \%)$ & $13(41 \%)$ & $9(16 \%)$ & .01 \\
\hline COPD & $26(30 \%)$ & $11(36 \%)$ & $15(27 \%)$ & .3 \\
\hline Prior cardiac surgery & $42(48 \%)$ & $17(53 \%)$ & $25(45 \%)$ & .5 \\
\hline Beta-blockers & $58(57 \%)$ & $25(86 \%)$ & $33(60 \%)$ & .02 \\
\hline ACE inhibitors & $40(46 \%)$ & $11(40 \%)$ & $29(53 \%)$ & .2 \\
\hline NYHA class (I-IV) & $3 \pm 0.5$ & $3 \pm 0.6$ & $3 \pm 0.5$ & .9 \\
\hline BUN (mg/dL) & $23 \pm 8$ & $22 \pm 7$ & $24 \pm 9$ & .5 \\
\hline Creatinine (mg/dL) & $1 \pm 0.3$ & $1.02 \pm 0.6$ & $1.01 \pm 0.31$ & .5 \\
\hline Additive EuroSCORE & $13.0 \pm 1.8$ & $13.3 \pm 1.7$ & $12.8 \pm 1.8$ & .2 \\
\hline
\end{tabular}

$A V R$, Aortic valve replacement; TAVR, transcatheter aortic valve replacement; $C O P D$, chronic obstructive pulmonary disease; $A C E$, angiotensin-converting enzyme; NYHA, New York Heart Association; BUN, blood urea nitrogen. 
TABLE 2. Baseline echocardiographic characteristics of the study population

\begin{tabular}{|c|c|c|c|c|}
\hline Variable & Total group $(n=87)$ & Surgical AVR group $(n=32)$ & TAVR group $(n=55)$ & $P$ value \\
\hline LV ejection fraction $(\%)$ & $51 \pm 13$ & $48 \pm 14$ & $53 \pm 13$ & .1 \\
\hline LV end-diastolic dimension $(\mathrm{cm})$ & $4.7 \pm 0.9$ & $4.8 \pm 1.1$ & $4.6 \pm 0.8$ & .4 \\
\hline LV end-systolic dimension $(\mathrm{cm})$ & $3.3 \pm 1$ & $3.6 \pm 1.3$ & $3.2 \pm 1$ & .08 \\
\hline $\mathrm{AV}$ peak gradient $(\mathrm{mm} \mathrm{Hg})$ & $78 \pm 22$ & $74 \pm 18$ & $79 \pm 24$ & .3 \\
\hline $\mathrm{AV}$ mean gradient $(\mathrm{mm} \mathrm{Hg})$ & $46 \pm 13$ & $45 \pm 11$ & $46 \pm 14$ & 6 \\
\hline $\mathrm{AV}$ area $\left(\mathrm{cm}^{2}\right)$ & $0.6 \pm 0.1$ & $0.62 \pm 0.1$ & $0.63 \pm 0.1$ & .5 \\
\hline LV outflow tract diameter $(\mathrm{cm})$ & $1.96 \pm 0.2$ & $2.03 \pm 0.1$ & $1.92 \pm 0.2$ & .02 \\
\hline AR $(\mathrm{I}-\mathrm{IV}+)$ & $1.0 \pm 0.7$ & $0.86 \pm 0.7$ & $1.1 \pm 0.8$ & .2 \\
\hline MR (I-IV+) & $1.3 \pm 0.8$ & $1.4 \pm 0.7$ & $1.2 \pm 0.8$ & .2 \\
\hline TR $(\mathrm{I}-\mathrm{IV}+)$ & $1.2 \pm 0.9$ & $1.2 \pm 0.9$ & $1.2 \pm 0.9$ & .9 \\
\hline RV systolic pressure (mm Hg) & $43 \pm 17$ & $42 \pm 15$ & $44 \pm 17$ & .5 \\
\hline
\end{tabular}

$A V R$, Aortic valve replacement; $T A V R$, transcatheter aortic valve replacement; $A V$, aortic valve; $L V$, left ventricular; $A R$, aortic regurgitation; $M R$, mitral regurgitation; $T R$, tricuspid regurgitation; $R V$, right ventricular.

\section{Postprocedural Findings in Surgical AVR and TAVR Groups}

There were no intraprocedural deaths in either group. The predischarge echocardiographic findings are shown in Table 4. A significantly higher proportion of patients had postprocedural paravalvular AR (mild or more) in the TAVR than in the surgical AVR group (58\% vs $34 \%$; $P<.03)$. Within the surgical AVR group, 2 patients had $2+$ residual AR; the rest had mild $(1+)$ AR. On the other hand, moderate or higher degree of postprocedural paravalvular AR was seen in $5(9 \%)$ patients in the TAVR group. The paravalvular aortic regurgitant vena contracta was significantly higher in the TAVR group than in the surgical $\operatorname{AVR}$ group $(2 \pm 0.16$ vs $1 \pm 1.3 ; P=.03)$. Otherwise, there were no significant differences in the 2 subgroups.

\section{Analysis of the TAVR Group}

We further explored the imaging characteristics of the TAVR group $(\mathrm{n}=55)$, separated into 2 subgroups on the basis of degree of paravalvular AR: (1) trivial AR, $\mathrm{n}=23$ ) and (2) at least mild AR $(n=32)$. The findings are shown in Table 5. There was a significantly higher degree of annular (but not leaflet) calcification in the nontrivial AR group as compared with the trivial AR group. The deformation of the annular circumference and area were significantly lower (suggesting a "stiffer" annulus) in the mild or more AR group as compared with the trivial AR group. A significantly higher proportion of patients in the nontrivial AR group had an undersized prosthetic valve, defined as a negative prosthetic valve to annular circumference ratio $(74 \%$ vs $33 \% ; P=.004)$. The eccentricity index was similar in

TABLE 3. Baseline MDCT characteristics of the study population

\begin{tabular}{|c|c|c|c|c|}
\hline Variable & Total group $(\mathbf{n}=\mathbf{8 7})$ & Surgical AVR group $(n=32)$ & TAVR group $(\mathbf{n}=\mathbf{5 5})$ & $P$ value \\
\hline Minimal annular circumference (mm) & $77 \pm 9$ & $76 \pm 8$ & $77 \pm 10$ & .5 \\
\hline Maximal annular circumference (mm) & $80 \pm 9$ & $79 \pm 8$ & $80 \pm 10$ & .5 \\
\hline $\begin{array}{l}\text { Deformation in annular circumference during } \\
\text { cardiac cycle }(\mathrm{mm})\end{array}$ & $3 \pm 1$ & $3 \pm 1$ & $3 \pm 1$ & .7 \\
\hline Minimal annular area $\left(\mathrm{mm}^{2}\right)$ & $445 \pm 102$ & $435 \pm 89$ & $450 \pm 109$ & .5 \\
\hline Maximal annular area $\left(\mathrm{mm}^{2}\right)$ & $482 \pm 111$ & $472 \pm 98$ & $488 \pm 118$ & .5 \\
\hline $\begin{array}{l}\text { Deformation in annular area during cardiac } \\
\text { cycle }\left(\mathrm{mm}^{2}\right)\end{array}$ & $38 \pm 17$ & $37 \pm 17$ & $38 \pm 17$ & .9 \\
\hline Minimal largest diameter (mm) & $25 \pm 3$ & $25 \pm 3$ & $25 \pm 3$ & .9 \\
\hline Maximal largest diameter (mm) & $26 \pm 3$ & $26 \pm 3$ & $26 \pm 3$ & .8 \\
\hline $\begin{array}{l}\text { Deformation in largest diameter during } \\
\text { cardiac cycle }(\mathrm{mm})\end{array}$ & $1.2 \pm 0.5$ & $1.1 \pm 0.6$ & $1.3 \pm 0.5$ & .2 \\
\hline Minimal smallest diameter (mm) & $20 \pm 3$ & $20 \pm 3$ & $20 \pm 4$ & .8 \\
\hline Maximal smallest diameter (mm) & $21 \pm 3$ & $22 \pm 3$ & $21 \pm 3$ & .8 \\
\hline $\begin{array}{l}\text { Deformation in smallest diameter during } \\
\text { cardiac cycle }(\mathrm{mm})\end{array}$ & $1.2 \pm 0.5$ & $1.2 \pm 0.7$ & $1.2 \pm 0.4$ & .8 \\
\hline Eccentricity index & $1.2 \pm 0.1$ & $1.2 \pm 0.1$ & $1.2 \pm 0.1$ & .9 \\
\hline Commissural calcification & $2.1 \pm 0.7$ & $2.0 \pm 0.7$ & $2.1 \pm 0.6$ & .6 \\
\hline Annular calcification & $1.7 \pm 0.7$ & $1.7 \pm 0.8$ & $1.7 \pm 0.8$ & .9 \\
\hline
\end{tabular}

$M D C T$, Multidetector computed tomography; $A V R$, aortic valve replacement; $T A V R$, transcatheter aortic valve replacement. 


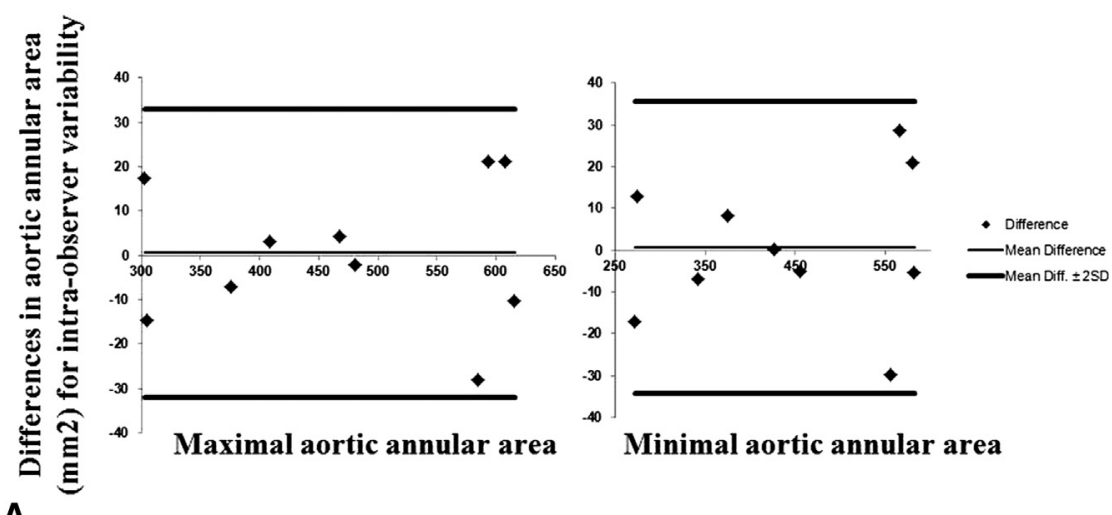

A
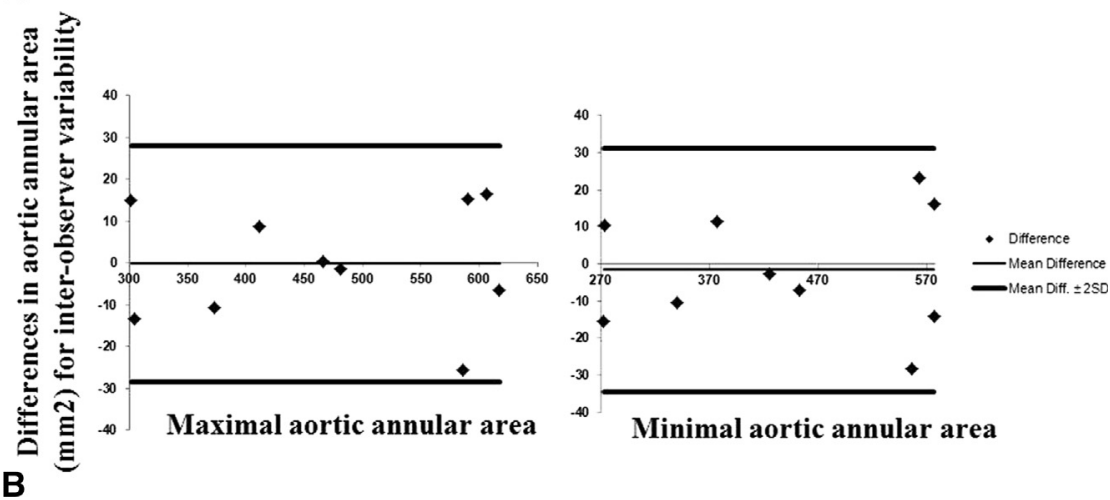

FIGURE 2. A, Bland-Altman graphs showing intraobserver variability for maximal and minimal aortic annular area $\left(\mathrm{mm}^{2}\right)$. B, Bland-Altman graphs showing interobserver variability for maximal and minimal aortic annular area $\left(\mathrm{mm}^{2}\right) . S D$, Standard deviation.

both subgroups. The deployment height was also similar in 2 subgroups. No patient had a malpositioned prosthesis, and none required a valve-in-valve procedure. On receiver operator characteristic curve analysis, the area under the curve for degree of annular circumferential deformation predicting mild or greater post-TAVR AR was significant $(0.72$; $P<.001$; Figure 3 ). A cutoff value of less than $3 \mathrm{~mm}$ for annular circumferential deformation had a sensitivity of $74 \%$ and specificity of $72 \%$ for prediction of nontrivial postTAVR AR. Similarly, the area under the curve for degree of annular area deformation was also significant $(0.69$; $P<.001)$.
Subsequently, we performed logistic regression analysis to test for predictors of nontrivial AR in the TAVR group. The results are shown in Table 6. On multivariable analysis, in addition to higher annular calcification and prosthesis undersizing, reduced annular deformation remained independent predictors of nontrivial AR. The results were similar when deformation of annular area was substituted for annular circumference. In the study population, only 5 patients in the TAVR group had moderate or more residual AR. Although the deformation of annular area during the cardiac cycle did not reach statistical significance, it was indeed lower (suggesting a trend toward a stiffer annulus) in

TABLE 4. Postprocedural echocardiographic characteristics of the study population

\begin{tabular}{|c|c|c|c|c|}
\hline Variable & Total group $(n=87)$ & Surgical AVR group $(n=32)$ & TAVR group $(n=55)$ & $P$ value \\
\hline LV ejection fraction $(\%)$ & $52 \pm 11$ & $49 \pm 12$ & $53 \pm 11$ & .2 \\
\hline AV mean gradient $(\mathrm{mm} \mathrm{Hg})$ & $22 \pm 11$ & $11 \pm 6$ & $11 \pm 5$ & .9 \\
\hline $\mathrm{AV}$ peak gradient $(\mathrm{mm} \mathrm{Hg})$ & $11 \pm 6$ & $23 \pm 11$ & $22 \pm 11$ & .9 \\
\hline Aortic regurgitant vena contracta & $0.19 \pm 0.2$ & $0.1 \pm 0.1$ & $0.2 \pm 0.2$ & .03 \\
\hline Patients with more than trivial $\mathrm{AR}$ & $34(39 \%)$ & $11(34 \%)$ & $32(58 \%)$ & .03 \\
\hline MR (I-IV) & $0.9 \pm 0.6$ & $1 \pm 0.8$ & $0.9 \pm 0.5$ & .4 \\
\hline TR (I-IV) & $1.2 \pm 0.8$ & $1.2 \pm 0.9$ & $1.2 \pm 0.1$ & .9 \\
\hline $\mathrm{RV}$ systolic pressure $(\mathrm{mm} \mathrm{Hg})$ & $40 \pm 12$ & $40 \pm 11$ & $40 \pm 12$ & .9 \\
\hline
\end{tabular}

$\overline{A V R}$, Aortic valve replacement; $T A V R$, transcatheter aortic valve replacement; $L V$, left ventricular; $A V$, aortic valve; $A R$, aortic regurgitation; $M R$, mitral regurgitation; $T R$, tricuspid regurgitation; $R V$, right ventricular. 
TABLE 5. Clinical and imaging characteristics of the TAVR group

\begin{tabular}{|c|c|c|c|}
\hline Variable & Trivial AR $(\mathbf{n}=23)$ & More than trivial AR $(\mathrm{n}=32)$ & $P$ value \\
\hline Age (y) & $79 \pm 11$ & $80 \pm 11$ & .9 \\
\hline Gender $(\%)$ & $12(52 \%)$ & $16(50 \%)$ & .5 \\
\hline LV ejection fraction $(\%)$ & $53 \pm 13$ & $52 \pm 14$ & .9 \\
\hline Mean AV gradient (mm Hg) & $48 \pm 17$ & $45 \pm 12$ & .5 \\
\hline $\mathrm{AV}$ area $\left(\mathrm{cm}^{2}\right)$ & $0.63 \pm 0.1$ & $0.64 \pm 0.13$ & .7 \\
\hline LV outflow tract $(\mathrm{cm})$ & $1.9 \pm 0.2$ & $1.9 \pm 0.2$ & .8 \\
\hline RV systolic pressure (mm $\mathrm{Hg}$ ) & $42 \pm 15$ & $46 \pm 19$ & .4 \\
\hline Commissural calcification & $2 \pm 0.5$ & $2.2 \pm 0.7$ & .2 \\
\hline Annular calcification & $1.4 \pm 0.6$ & $1.8 \pm 0.02$ & .02 \\
\hline Deformation in annular circumference during cardiac cycle (mm) & $3.6 \pm 1.3$ & $2.6 \pm 0.8$ & .001 \\
\hline Deformation in annular area during cardiac cycle $\left(\mathrm{mm}^{2}\right)$ & $46 \pm 21$ & $32 \pm 10$ & .003 \\
\hline Deformation in largest diameter during cardiac cycle (mm) & $1.4 \pm 0.5$ & $1.1 \pm 0.4$ & .05 \\
\hline Deformation in smallest diameter during cardiac cycle (mm) & $1.2 \pm 0.5$ & $1.2 \pm 0.4$ & 6 \\
\hline Prosthetic valve to annular circumference sizing ratio $(\%)$ & $-0.03 \pm 7$ & $-7 \pm 10$ & .007 \\
\hline Eccentricity index & $1.3 \pm 0.2$ & $1.2 \pm 0.1$ & .3 \\
\hline Prosthetic valve position ratio & $0.33 \pm 0.1$ & $0.34 \pm 0.1$ & .7 \\
\hline
\end{tabular}

$T A V R$, Transcatheter aortic valve replacement; $A R$, aortic regurgitation; $L V$, left ventricular; $A V$, aortic valve; $R V$, right ventricular.

the moderate-severe AR group as compared with the mild or lesser AR group $\left(32 \pm 9 \mathrm{~mm}^{2}\right.$ vs $\left.38 \pm 9 \mathrm{~mm}^{2} ; P=.3\right)$.

\section{DISCUSSION}

In the current study, we demonstrate that patients undergoing TAVR had a higher degree of paravalvular AR than did those undergoing surgical AVR. We demonstrate that reduced deformation (suggesting reduced compliance) of annular circumference was a predictor of nontrivial AR after TAVR. This association was independent of established predictors of post-TAVR AR (prosthetic valve undersizing and annular calcification, which have been previously described). ${ }^{7,8,18}$ The results were similar when deformation of annular area during the cardiac cycle was substituted for deformation of annular circumference. These results,

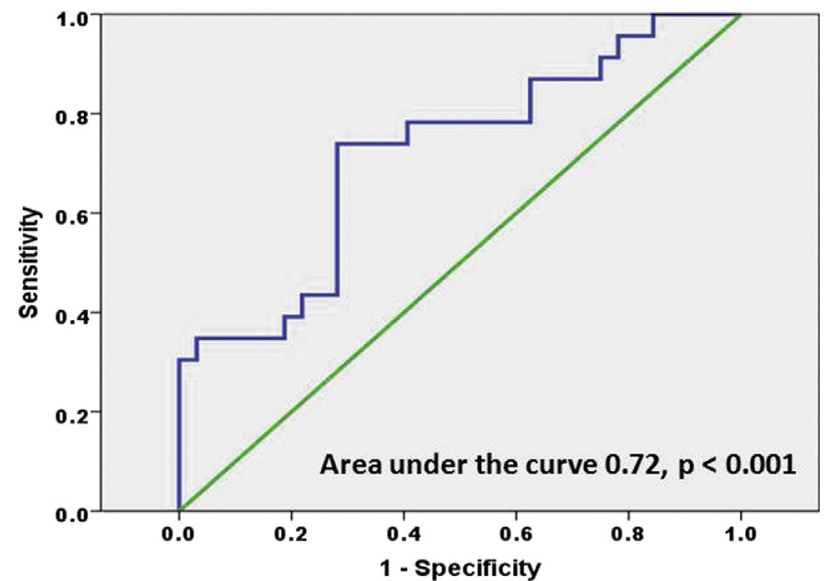

FIGURE 3. Receiver operator characteristic curve analysis showing the area under the curve for ability of aortic annular circumferential deformability to predict mild or more aortic regurgitation in patients undergoing transcatheter aortic valve replacement. obtained with an advanced time-resolved (4-dimensional) analysis, provide important insights into the interaction between stent/valve and annulus and demonstrate the impact of device landing zone deformability on procedural outcomes. In the current study, neither aortic annular eccentricity nor position of valvular prosthesis vis-à-vis the annulus was associated with post-procedural AR.

The study population was typical of those undergoing evaluation followed by high-risk AVR (either TAVR or surgical). The study population was old with a relatively high proportion of conventional risk factors and a high EuroSCORE. Other than difference in the degree of postprocedural AR, there were no significant differences in the clinical and imaging characteristics of patients who underwent surgical AVR versus TAVR. The proportion of postprocedural AR in the surgical AVR group was higher than what has been reported previously; this is likely because of older population in the current study with higher degree of annular calcification. ${ }^{19}$ However, only 2 patients had moderate $(2+)$ paravalvular aortic valve leak; the rest had mild $(1+)$ residual AR.

During surgical AVR, sewing of the annulus on the valve ring forces the annulus into the shape required for a tight fit. In contrast, during TAVR, device deployment is associated with incompletely understood interaction between the expanding stent valve and the compliance of the landing zone. Not surprisingly, our data and prior studies demonstrate a higher proportion of AR in high-risk patients undergoing TAVR versus surgical AVR, despite similar baseline and imaging characteristics. ${ }^{4}$ Although, traditionally, moderate or severe AR has been thought to be associated worse outcomes, the presence of mild or more post-TAVR AR has assumed increased clinical significance since it was recently associated with worse outcomes. ${ }^{4}$

Post-TAVR AR is very likely related to an undersized stent valve or focal incomplete coaptation secondary to 
TABLE 6. Univariable and multivariable logistic regression analysis evaluating the predictors of postprocedural aortic insufficiency in the TAVR group

\begin{tabular}{|c|c|c|c|c|}
\hline \multirow[b]{2}{*}{ Variable } & \multicolumn{2}{|c|}{ Univariable } & \multicolumn{2}{|c|}{ Multivariable } \\
\hline & $\begin{array}{c}\text { Wald } \\
\text { statistic }\end{array}$ & $P$ value & $\begin{array}{c}\text { Wald } \\
\text { statistic }\end{array}$ & $P$ value \\
\hline Age & 0.006 & .9 & & \\
\hline Gender & 0.03 & .9 & & \\
\hline Hypertension & 0.42 & .5 & & \\
\hline Diabetes mellitus & 0.4 & .5 & & \\
\hline Myocardial infarction & 0.9 & .3 & & \\
\hline Beta-blockers & 0.2 & .7 & & \\
\hline Preprocedural ejection fraction & 0.005 & .9 & & \\
\hline LV end-diastolic dimension & 1.17 & .3 & & \\
\hline LV end-systolic dimension & 0.05 & .8 & & \\
\hline Diastolic dysfunction & 0.69 & .4 & & \\
\hline Mean AV gradient & 0.56 & .5 & & \\
\hline $\mathrm{AV}$ area & 1.11 & .6 & & \\
\hline Preprocedure AR & 2.9 & .09 & & \\
\hline Commissural calcification & 1.12 & .3 & & \\
\hline Annular calcification & 4.9 & .03 & 4.4 & .03 \\
\hline Eccentricity index & 1.12 & .3 & & \\
\hline $\begin{array}{l}\text { Deformation of annular } \\
\text { circumference during cardiac } \\
\text { cycle }\end{array}$ & 8.99 & .003 & 6.6 & .01 \\
\hline Valve prosthesis: size 23 or 26 & 1.7 & .2 & & \\
\hline Prosthesis position ratio & 0.14 & .7 & & \\
\hline $\begin{array}{l}\text { Prosthesis to annular } \\
\text { circumference sizing ratio }\end{array}$ & 6.5 & .01 & 4.3 & .03 \\
\hline Postprocedural ejection fraction & 0.02 & .9 & & \\
\hline
\end{tabular}

deviation from a perfect circular postprocedural anatomy (owing to reduced deformation and/or annular calcification). An expanding literature demonstrates that undersizing can be avoided with careful preprocedural measurements. ${ }^{7,8}$ In contrast, prediction of focal coaptation is more difficult, in particular because of the complex and dynamic shape of the annulus and concomitant annular calcification. Multiple prior studies have demonstrated the oval shape of the annulus, ${ }^{16,20,21}$ and recent studies have shown that the aortic annulus geometry changes during the cardiac cycle. $^{6,9,10}$

Multiple studies have examined imaging-derived predictors of procedural complications and specifically postprocedural AR. ${ }^{6-8}$ They have demonstrated that annular calcification and valve undersizing are important contributors of residual post-TAVR AR. However, none of these studies has systematically evaluated dynamic deformation of the aortic annulus. Recent advances in software technology allow advanced high temporal resolution time-resolved 3-dimensional CT reconstruction (ie, 4-dimensional reconstruction) by integration and interpolation of multiple image sets along the cardiac cycle. With this approach, our results, for the first time, demonstrate that annular deformability has an impact on postprocedural AR. The differences in annular deformity in patients with significant versus nonsignificant post-TAVR AR were subtle, likely because of the homogeneity of the study population (all were older high-risk AS patients). To demonstrate differences in deformability, we need to study patients with a wider spectrum of age and disease severity to establish thresholds of normal values of deformation of the aortic annulus. Once the thresholds are established, they could be used to identify patients who have a stiffer annulus (less deformability), which could help predict post-TAVR AR. Another potential utility is probably to help design future stents that are more malleable and confirm to the dynamic nature of the annulus.

\section{Limitations}

This is a small observational study of patients who were able to have a contrast-enhanced CT scan followed by AVR. Hence, there is insufficient power to evaluate hard outcomes. As an initial step, we wanted to ascertain that there indeed was a higher prevalence of AR in the TAVR as compared with the surgical group. As a result, we report data on both surgical and TAVR groups, followed by a detailed analysis of the TAVR group. The concept of 3-dimensional assessment of the aortic annulus is a rapidly evolving one. When the current study population was imaged, the standard of care was to use 2-dimensional echocardiography (obtained on surface echocardiography and subsequently confirmed by TEE in the catheterization laboratory) to obtain annular measurements and decide on appropriate valve size. It is only recently that 3-dimensional measurements have become more prevalent. As a result, those were not uniformly available and, hence, not reported. Annular calcification was performed semiquantitatively, rather a calcium score (which is not validated in contrast-enhanced studies). In older TAVR patients, iodinated contrast is associated with increased risk of nephrotoxicity. However, in the current study, no patient had significant post-CT scan nephrotoxicity. Although MDCT is also associated with significant radiation exposure, the risks of long-term deleterious effects of radiation are of lesser concern in older TAVR patients. As a result, a reasonable compromise would be to avoid radiation dose modulation to maintain optimal image quality. Still, for the MDCT community, it is important to continue to work on minimizing radiation exposure. With availability of newer imaging techniques, the concept of aggressive radiation reduction is rapidly evolving. We divided postprocedural AR into trivial and nontrivial, with nontrivial defined as AR equal to or greater than mild. This definition appears controversial, inasmuch as current clinical practice typically differentiates between mild and significant (ie, $\geq$ III+) AR. However, this may not apply to TAVR, inasmuch as recent studies demonstrate that presence of nontrivial, post-TAVR AR was associated with increased mortality. ${ }^{4}$ 


\section{CONCLUSIONS}

In high-risk symptomatic patients with severe AS, there is a higher incidence of postprocedural nontrivial $A R$ in the TAVR group as compared with the surgical AVR group. Using 4-dimensional MDCT imaging, we demonstrate that reduced deformation of annular circumference during the cardiac cycle, in addition to prosthesis undersizing and annular calcification, is an independent predictor of postprocedural AR. These results provide important insights into the interaction between the stent/valve and the aortic annulus and demonstrate the impact of device landing zone deformability on TAVR outcomes.

We thank Richard Bennett of Qi systems, Redwood City, California, for supplying the Ziostation Physiodynamics work station.

\section{References}

1. Leon MB, Smith CR, Mack M, Miller DC, Moses JW, Svensson LG, et al. Transcatheter aortic-valve implantation for aortic stenosis in patients who cannot undergo surgery. N Engl J Med. 2010;363:1597-607.

2. Makkar RR, Fontana GP, Jilaihawi H, Kapadia S, Pichard AD, Douglas PS, et al. Transcatheter aortic-valve replacement for inoperable severe aortic stenosis. N Engl J Med. 2012;366:1696-704.

3. Smith CR, Leon MB, Mack MJ, Miller DC, Moses JW, Svensson LG, et al. Transcatheter versus surgical aortic-valve replacement in high-risk patients. N Engl J Med. 2011;364:2187-98.

4. Kodali SK, Williams MR, Smith CR, Svensson LG, Webb JG, Makkar RR, et al. Two-year outcomes after transcatheter or surgical aortic-valve replacement. N Engl J Med. 2012;366:1686-95.

5. Holmes DR Jr, Mack MJ, Kaul S, Agnihotri A, Alexander KP, Bailey SR, et al. ACCF/AATS/SCAI/STS expert consensus document on transcatheter aortic valve replacement: developed in collabration with the American Heart Association, American Society of Echocardiography, European Association for CardioThoracic Surgery, Heart Failure Society of America, Mended Hearts, Society of Cardiovascular Anesthesiologists, Society of Cardiovascular Computed Tomography, and Society for Cardiovascular Magnetic Resonance. J Thorac Cardiovasc Surg. 2012;144:e29-84.

6. Jilaihawi H, Kashif M, Fontana G, Furugen A, Shiota T, Friede G, et al. Crosssectional computed tomographic assessment improves accuracy of aortic annular sizing for transcatheter aortic valve replacement and reduces the incidence of paravalvular aortic regurgitation. J Am Coll Cardiol. 2012;59:1275-86.

7. Willson AB, Webb JG, Labounty TM, Achenbach S, Moss R, Wheeler M, et al. 3-Dimensional aortic annular assessment by multidetector computed tomography predicts moderate or severe paravalvular regurgitation after transcatheter aortic valve replacement: a multicenter retrospective analysis. J Am Coll Cardiol. 2012;59:1287-94.

8. Buzzatti N, Maisano F, Latib A, Cioni M, Taramasso M, Mussardo M, et al. Computed tomography-based evaluation of aortic annulus, prosthesis size and impact on early residual aortic regurgitation after transcatheter aortic valve implantation. Eur J Cardiothorac Surg. 2013;43:43-50; discussion 50-1.

9. Hamdan A, Guetta V, Konen E, Goitein O, Segev A, Raanani E, et al. Deformation dynamics and mechanical properties of the aortic annulus by 4-dimensional computed tomography: insights into the functional anatomy of the aortic valve complex and implications for transcatheter aortic valve therapy. J Am Coll Cardiol. 2012;59:119-27.

10. Bertaso AG, Wong DT, Liew GY, Cunnington MS, Richardson JD, Thomson VS, et al. Aortic annulus dimension assessment by computed tomography for transcatheter aortic valve implantation: differences between systole and diastole. Int $J$ Cardiovasc Imaging. 2012;28:2091-8.

11. Baumgartner H, Hung J, Bermejo J, Chambers JB, Evangelista A, Griffin BP, et al. Echocardiographic assessment of valve stenosis: EAE/ASE recommendations for clinical practice. J Am Soc Echocardiogr. 2009;22:1-23; quiz 101-2.

12. Nashef SA, Roques F, Michel P, Gauducheau E, Lemeshow S, Salamon R. European system for cardiac operative risk evaluation (EuroSCORE). Eur J Cardiothorac Surg. 1999;16:9-13.

13. Lang RM, Bierig M, Devereux RB, Flachskampf FA, Foster E, Pellikka PA, et al. Recommendations for chamber quantification: a report from the American Society of Echocardiography's Guidelines and Standards Committee and the Chamber Quantification Writing Group, developed in conjunction with the European Association of Echocardiography, a branch of the European Society of Cardiology. J Am Soc Echocardiogr. 2005;18:1440-63.

14. Zoghbi WA, Chambers JB, Dumesnil JG, Foster E, Gottdiener JS, Grayburn PA, et al. Recommendations for evaluation of prosthetic valves with echocardiography and Doppler ultrasound: a report From the American Society of Echocardiography's Guidelines and Standards Committee and the Task Force on Prosthetic Valves, developed in conjunction with the American College of Cardiology Cardiovascular Imaging Committee, Cardiac Imaging Committee of the American Heart Association, the European Association of Echocardiography, a registered branch of the European Society of Cardiology, the Japanese Society of Echocardiography and the Canadian Society of Echocardiography, endorsed by the American College of Cardiology Foundation, American Heart Association, European Association of Echocardiography, a registered branch of the European Society of Cardiology, the Japanese Society of Echocardiography, and Canadian Society of Echocardiography. J Am Soc Echocardiogr. 2009;22: 975-1014; quiz 1082-4.

15. Leipsic J, Gurvitch R, Labounty TM, Min JK, Wood D, Johnson M, et al. Multidetector computed tomography in transcatheter aortic valve implantation. JACC Cardiovasc Imaging. 2011;4:416-29.

16. Messika-Zeitoun D, Serfaty JM, Brochet E, Ducrocq G, Lepage L, Detaint D, et al. Multimodal assessment of the aortic annulus diameter: implications for transcatheter aortic valve implantation. J Am Coll Cardiol. 2010;55:186-94.

17. Leon MB, Piazza N, Nikolsky E, Blackstone EH, Cutlip DE, Kappetein AP, et al. Standardized endpoint definitions for transcatheter aortic valve implantation clinical trials: a consensus report from the Valve Academic Research Consortium. Eur Heart J. 2011;32:205-17.

18. John D, Buellesfeld L, Yuecel S, Mueller R, Latsios G, Beucher H, et al. Correlation of Device landing zone calcification and acute procedural success in patients undergoing transcatheter aortic valve implantations with the selfexpanding CoreValve prosthesis. JACC Cardiovasc Interv. 2010;3:233-43.

19. Sponga S, Perron J, Dagenais F, Mohammadi S, Baillot R, Doyle D, et al. Impact of residual regurgitation after aortic valve replacement. Eur J Cardiothorac Surg. 2012;42:486-92.

20. O'Brien B, Schoenhagen P, Kapadia SR, Svensson LG, Rodriguez L, Griffin BP, et al. Integration of 3D imaging data in the assessment of aortic stenosis: impact on classification of disease severity. Circ Cardiovasc Imaging. 2011;4:566-73.

21. Tops LF, Wood DA, Delgado V, Schuijf JD, Mayo JR, Pasupati S, et al. Noninvasive evaluation of the aortic root with multislice computed tomography implications for transcatheter aortic valve replacement. JACC Cardiovasc Imaging. 2008;1:321-30. 